\title{
Study of Reactive Flow of Split-type Air Conditioners and Inverter Air Conditioners in the Consumer Units and the Public Electricity Companies
}

\author{
Marllon Welter Schlischting'1, Acad.; Gabriela Pessoa Campos ${ }^{1}$, Acad.; Arnulfo Barroso de Vasconcellos ${ }^{1}$, Dr.; Fabricio \\ Parra Santilio ${ }^{1}$, Dr.; Teresa Irene Ribeiro de Carvalho Malheiro, $\mathrm{PhD}^{2}$ and Raul Vitor Arantes Monteiro ${ }^{3}$, Msc.: \\ ${ }^{1}$ Faculty of Architecture, Engineering and Technology, UFMT -Federal University of Mato Grosso - Cuiabá/MT - Av. \\ Fernando Correa da Costa, 2367, Cuiabá (Brazil) \\ Phone: +55 (65) 3615-8000, e-mail: marllon.schlischting@gmail.com, gabriela_pessoacampos@ hotmail.com, \\ arnulfo@ufmt.br, parra@ufmt.br.
}
${ }^{2}$ Federal Institution of Education, Science and Technology of Mato Grosso - IFMT - Av. Sen. Filinto Müller , 953, Cuiabá (Brazil)
Phone: +55 (65) 3616-4100, e-mail: malheiro.teresa@ gmail .

${ }^{3}$ Federal University of Uberlândia, Science and Technology of Mato Grosso - UFU - Av. João Naves de Ávila, 2121,
Uberlândia (Brazil) Phone: +55 (34) 3239-4411, e-mail: rauldvm @ terra.com.br .

\begin{abstract}
This paper presents a study about the split-type and inverter air conditioners, in the context of billing and power quality. In field measurements using inverter air conditioners, it was observed that the injected reactive power flow on the bus is equivalent or greater than the consumed active power flow, thus influencing the power factor of the electrical system as these loads are connected to the system on a large scale. The measurements were performed with commercially available power quality analyzers and meters used for billing purposes. Therefore, from the point of view of sales of electricity, such loads are influencing the measurement of the power factor and therefore the reactive power.
\end{abstract}

\section{Key words}

Power Quality, Energy Billing, Reactive Power Flow, Potency factor, Air Conditioners.

\section{Introduction}

The use of electronic devices is growing every year, in all consumer segments. Such devices, due to the constructive aspects, have strong influence on issues related to the quality of the electricity, with a strong injection of positive, negative and zero sequence harmonics to the system and, therefore, should be considered in studies about electrical system.

Among these devices, the modern air conditioners may be mentioned. From the 60's, the appliances have become increasingly compact and quiet, and more efficient in electricity consumption. Split Inverter air conditioners were recently launched in Brazil, employing frequency inverters for reaching the desired temperature faster than conventional Split-type air conditioners [1].

When performing measurements in both field and laboratory, it has been observed in the billing equipment and in power quality analyzer, a capacitive reactive flow by the electronic loads, which can behave as a form of intrinsic compensation system.

According to the reference [2], the electronic energy meters can generate different results for the same network situation with high harmonic distortion. This means that electronic meters have different interpretations of the calculation of reactive power and also on the calculation of the power factor caused by different algorithms and measurement techniques used internally by these meters. The problem therefore lies in the fact that the reactive power is not defined precisely in the context of non-sinusoidal conditions. As a result, the tests of national and international standards do not include the behavior of reactive energy meters in the presence of harmonics. Thus, the reactive energy meters behavior when submitted in networks with harmonics has not been fully understood

Soon, this injection of reactive by the electronic loads, presented in meters, would be impacting the performance of the electrical system and also in the billing reactive energy, especially in predominantly inductive systems. Currently, only large consumers are penalized, via charging system, the reactive power surplus. Therefore, from the point of view of billing equipment, the behavior of reactive on electronic loads can help in reactive compensation, decreasing the amount of capacitor bank to be installed. Thus, this paper aims to analyze the reactive power flow of electronic loads, specifically air conditioners Split-type, comparing conventional and Inverter technologies.

\section{Billing of Reactive Energy Surplus in the Brazilian Electric System}


Currently, the electricity consumers of group A (large consumers) and some group B (small consumers) are responsible for the use of electricity delivered to your establishment and can be billed not only for the useful portion of energy used, which is transformed into work, but also by the share that is not transformed into work, but is required by the customer load.

In Brazil, the National Electric Energy Agency (ANEEL) is responsible for normalizing the electricity sector. The General Conditions of Electricity Supply are determined by the Normative Resolution No. 414 of September 9, 2010 [3]. This resolution considers that for consumers of group A, the reference power factor "fr", inductive or capacitive, has as minimum allowed limit, the value of 0.92 .

"To electricity amounts and reactive power demand which exceed the permitted level, apply the charges set forth in arts. 96 and 97, to be added to the regular billing group of consumer units $\mathrm{A}$, including those who choose to revenue from the application of Group B tariff under art. 100. "(Normative Resolution $\mathrm{n}^{\circ} 414,2010$, p. 84).

"Art 96. - For consumer unit that has appropriate measuring equipment, including one whose owner has signed the Contract for Use of Distribution System CUSD, the values corresponding to electricity and surplus reactive power demand are calculated according to the following equations:" (Normative Resolution No. 414, 2010, p. 84-87).

$$
\begin{gathered}
E_{R E}=\sum_{T=1}^{\pi 5}\left[E E A M_{T} \times\left(\frac{f r}{f t}-1\right)\right] \times V R_{E R E} \\
D_{R E}(p)=\left[\operatorname{MAX}\left(\operatorname{PAM}_{T} \times \frac{f r}{f t}\right)-P A F(p)\right] \times V R_{D R E}
\end{gathered}
$$

- $\mathrm{E}_{\mathrm{RE}}$ : amount corresponding to the reactive power over the amount allowed by the reference power factor "fr" in the billing period, in Reais ( $\mathrm{R} \$$, Brazilian currency);

- EEAM $_{\mathrm{T}}$ : amount of active power measured at each interval "T" of one (1) hour during the billing period in Megawatt-hour (MWh);

- fr: Reference power factor of 0.92;

- $\mathrm{ft}$ : power factor of the consumer unit, calculated at each interval " $\mathrm{T}$ " of one (1) hour during the billing period;

- $\mathrm{VR}_{\mathrm{ERE}}$ : reference value equivalent to the energy tariff "TE" applicable to subgroup B1, in Reais per megawatt-hour (R\$ / MWh);

- $D_{R E}(p)$ value, in each tariff position "p", corresponding to the demand for reactive power over the amount allowed by the reference power factor "fr" in the billing period, in Reais $(\mathrm{R} \$)$;

- $\mathrm{PAM}_{\mathrm{T}}$ : active power demand measure in the payment interval of one (1) hour "T" during the billing period, in kilowatt $(\mathrm{kW})$;

- $\operatorname{PAF}(\mathrm{p})$ : billable active power demand in each tariff position " $\mathrm{p} "$ in the billing period in kilowatt
$(\mathrm{kW})$;

- $\mathrm{VR}_{\mathrm{DRE}}$ : reference value, in Reais per kilowatt $(\mathrm{R} \$ / \mathrm{kW})$, equivalent to the power demand charges for off-peak tariff - of supply tariffs applicable to subgroups of group A for the Blue hourly tariff mode and TUSD (Tariff for Use of Distribution System) consumers-free, as is in force the Supply Agreement or the CUSD respectively;

- MAX: function that identifies the maximum value of the equation within the brackets corresponding, in each tariff position "p";

- $\mathrm{T}$ : indicates the range of one (1) hour in the billing period;

- $\mathrm{p}$ : indicates post tariff peak or off-peak to the hourly tariff arrangements or billing period for conventional tariff mode;

- $\mathrm{n} 1$ : intervals of payment " $\mathrm{T}$ " of the billing period for tariff positions peak and off-peak;

- $\mathrm{n} 2$ : intervals of payment " $\mathrm{T}$ ", in each tariff position " $\mathrm{p}$ " in the billing period.

So, as much as the amount to be paid is related to Reactive surplus, this is proportional to the amount of active power measurement in the time interval related to the measurement and the relation of the reference power factor with the power factor of the consumer unit.

For the calculation of these quantities, there is also a period of six (6) consecutive hours (at the discretion of the distributor) between $23 \mathrm{~h} 30 \mathrm{~min}$ and $6 \mathrm{~h} 30 \mathrm{~min}$, which is considered only the power factors "ft" less than 0.92 capacitive, checked at each interval of one hour " $T$ ". Complementing daily period, it is considered only the power factors below 0.92 inductive, recorded in the same time.

Therefore, as already stated, the electronic nature of the Inverter air conditioner means that it can directly influence the measurement of the amounts of reactive power surplus because, in theory, the injection of capacitive reactive on the bus contributes to the changes in the value of power factor recorded every hour. This foments two discussions in academic circles, the first about how relevant is this influence, due to the considerable increase of this type of load on residential, commercial and industrial buses. The second discussion is focused on the reactive power measurement method and consequently the power factor by the billing electronic meters in the presence of electronic loads with strong feature nonlinear.

\section{Harmonic Distortion in the Electrical System}

ANEEL published in 2008 the document "Electricity Distribution Procedures in the National Electric System PRODIST. This document is divided into 9 modules. Specifically, Module 8 - Power Quality "[4], provides reference values for voltage harmonic distortion (DTT) in the distribution system, as shown in Table I. 
Table I. - Reference Values of DTT

\begin{tabular}{|c|c|}
\hline BUS VOLTAGE & $\begin{array}{c}\text { TOTAL VOLTAGE HARMONIC } \\
\text { DISTORTION[\%] }\end{array}$ \\
\hline $\mathrm{Vn} \leq 1 \mathrm{kV}$ & 10 \\
\hline $1 \mathrm{kV} \leq \mathrm{Vn} \leq 13,8 \mathrm{kV}$ & 8 \\
\hline $13,8 \mathrm{kV} \leq \mathrm{Vn} \leq 69 \mathrm{kV}$ & 6 \\
\hline $69 \mathrm{kV} \leq \mathrm{Vn} \leq 138 \mathrm{kV}$ & 3 \\
\hline
\end{tabular}

Split Inverter Air conditioners have nonlinear characteristics, resulting in waveform currents with significant distortion. However, from the point of view of bus voltage, there were no significant distortions and are within the limits recommended by ANEEL Resolution No. 641, of January 1, 2015.[5]

Figs. 1 (a) to 1 (e) shows the equipment used to record the electrical parameters of air conditioners during the experiments: (a) MARH-21 RMS; (b) Fluke 434; (c) SAGA1000 Landis Gyr; (d) SAGA4500 Landis Gyr; e (e) SL7000 Actaris. The first two are registers meters quantities for single-phase electrical systems, two-phase and three-phase at low, medium and high voltage. The others are equipment used by utilities for electricity billing purposes of group A and B.

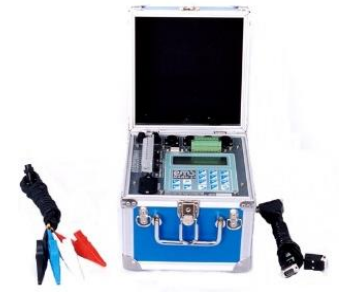

(a) RMS Marh21

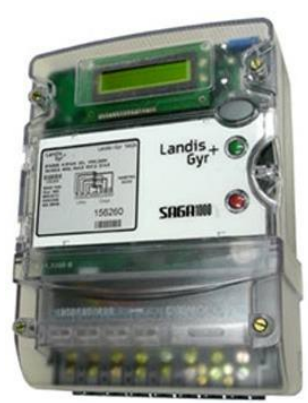

(c) SAGA1000 Landis Gyr

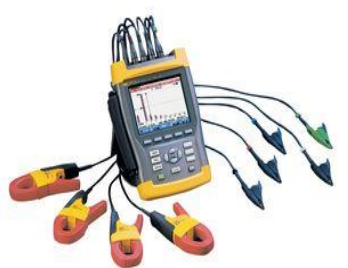

(b) Fluke 434

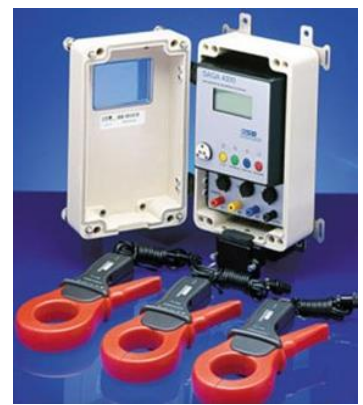

(d) SAGA4000 Landis Gyr

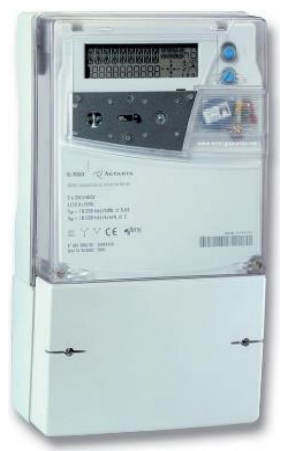

(e) SL7000 Actaris

Fig. 1. Measuring equipment used to check the power factor and reactive power flow.

\section{Measurements and Results}

Considering that the aim of this study is to analyze the reactive power flow and consequently the power factor, recorded by power quality analyzers, in the measurement of the Split-type air conditioners, two different types of air conditioning technologies 9000 BTU/h were used, often present in Consumer Units of groups A and B. The data of the selected devices are shown in Table II.

Table II. - Air Conditioners Characteristics

\begin{tabular}{|c|c|c|}
\hline AIR CONDITIONER & $\begin{array}{c}\text { REFRIGERATING } \\
\text { CAPACITY }\end{array}$ & VOLTAGE \\
\hline $\begin{array}{c}\text { Conventional } \\
\text { Split-type }\end{array}$ & $9000 \mathrm{BTU} / \mathrm{h}$ & $220 \mathrm{~V}$ \\
\hline $\begin{array}{c}\text { Inverter } \\
\text { Split-type }\end{array}$ & $9000 \mathrm{BTU} / \mathrm{h}$ & $220 \mathrm{~V}$ \\
\hline
\end{tabular}

Initially, measurements were made of waveforms of voltages, currents, besides the active and reactive power and power factor in both air conditioning models. Following the results and discussions are presented.

\section{A. Conventional Split-type Air Conditioner}

The Waveforms of voltage and current in the circuit that powers the conventional Split-type air conditioner are illustrated in Fig. 2, where it can be seen that the shape of the voltage waveform is almost sinusoidal, and the form of the current wave showed a total harmonic distortion (DTI) of $12.6 \%$, as the harmonic spectrum of the current shown in Fig. 3.

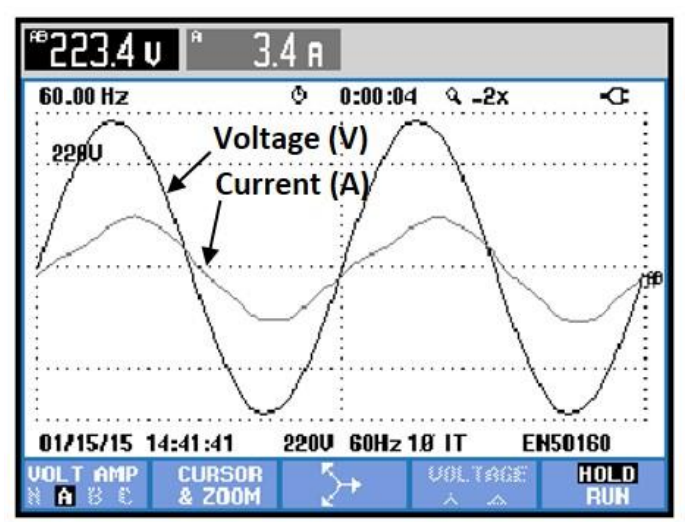

Fig. 2. Waveforms of Voltage and Current of conventional Split-type air conditioner.

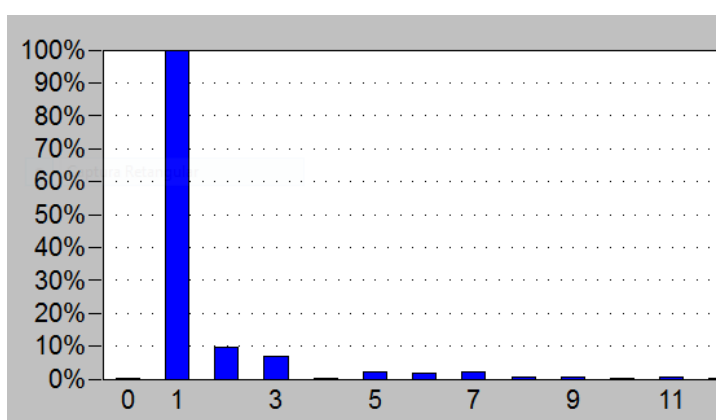

Fig. 3. Harmonic Spectrum of Conventional Split-type Air conditioner. 
Fig. 4 illustrates the vector diagram of voltage and current that feeds the respective air conditioning, obtained through the power quality analyzer Fluke 434. Note that the current lags the voltage.

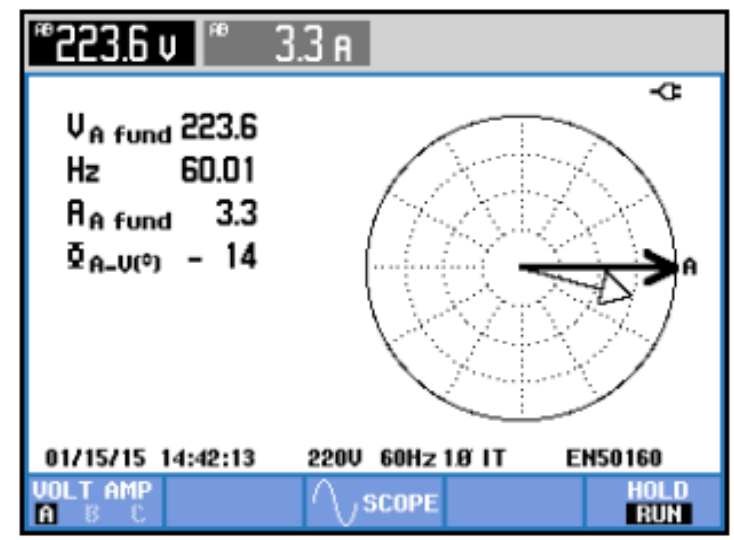

Fig. 4. Vector diagram of voltage and current.

Fig. 5 shows the active and reactive power flow on the bus and features a $700 \mathrm{~W}$ absorption of active power and a 200 Var absorption of inductive reactive power of electric energy dealership network. Fig. 5 also illustrates the difference between the offset factor that represents the cosine of the angle of current and voltage at $60 \mathrm{~Hz}$ (DPF), whose value is 0.97 , and the power factor (PF) that takes into account all frequencies present in the form of the current waveform, and this value of 0.96 . The relationship between active power and reactive power absorbed from the bus is illustrated in Fig. 6.

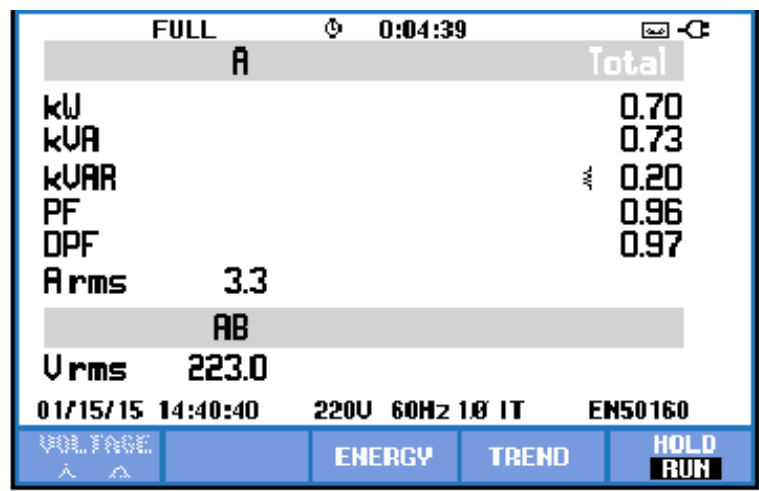

Fig. 5. Screenshot of power quality analyzer Fluke, indicating the inductive reactive power characteristic absorbed from the system by conventional split-type air conditioning.

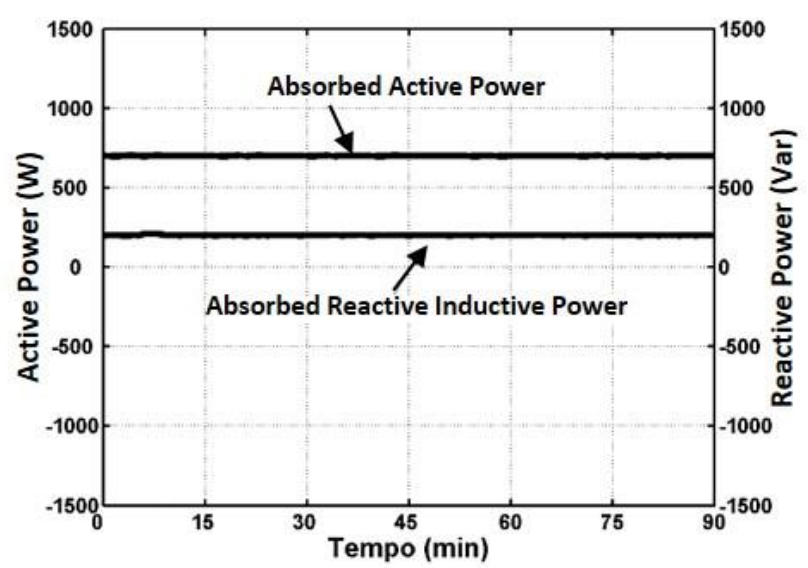

Fig. 6. Active power and inductive reactive power absorbed from the system by the conventional split-type air conditioning.

\section{B. Inverter Split-type Air Conditioner}

Continuing in behavior analysis of power quality and reactive flow of air conditioners, the second air conditioner split was analyzed, now the inverter splittype.

Fig. 7 illustrates the waveforms of the voltage and current applied by the device to the bus. The waveform voltage showed no significant harmonic distortion. Since the shape of the current showed a strong presence of harmonics and inter-harmonic positive, negative and zero sequence, making a total current distortion of $153.4 \%$ as illustrated in the current harmonic spectrum of Fig. 8.

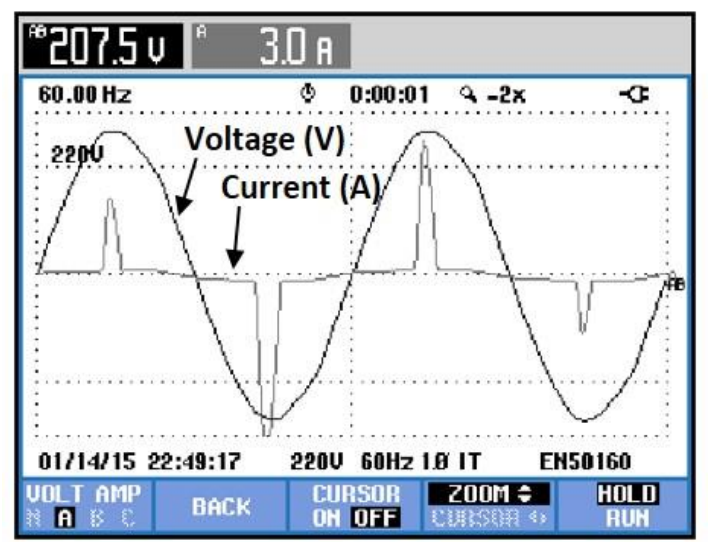

Fig. 7. Waveforms of the voltage and current of Inverter Splittype Air Conditioner.

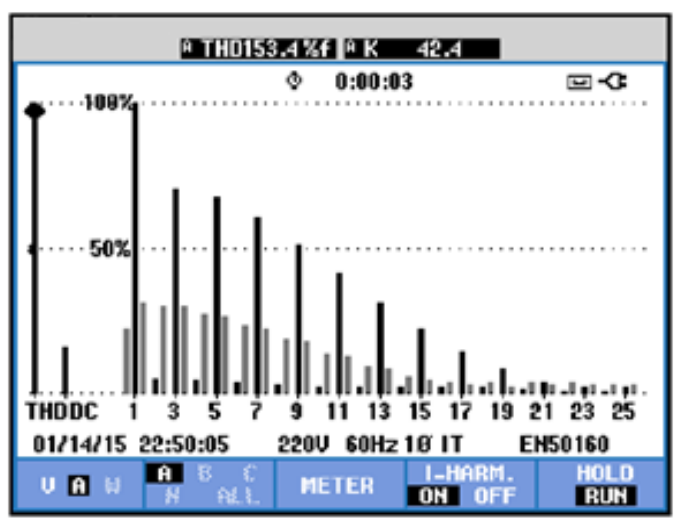

Fig. 8. Harmonic Spectrum of Inverter Split-type Air Conditioner.

In the vector diagram illustrated in Fig.9, it is clear that the current leads in relation to the voltage. In this way, there is the capacitive characteristic of the inverter splittype air conditioner as evidenced by the capacitor symbol shown in Fig.10, presented by the Fluke 434 power quality analyzer. 


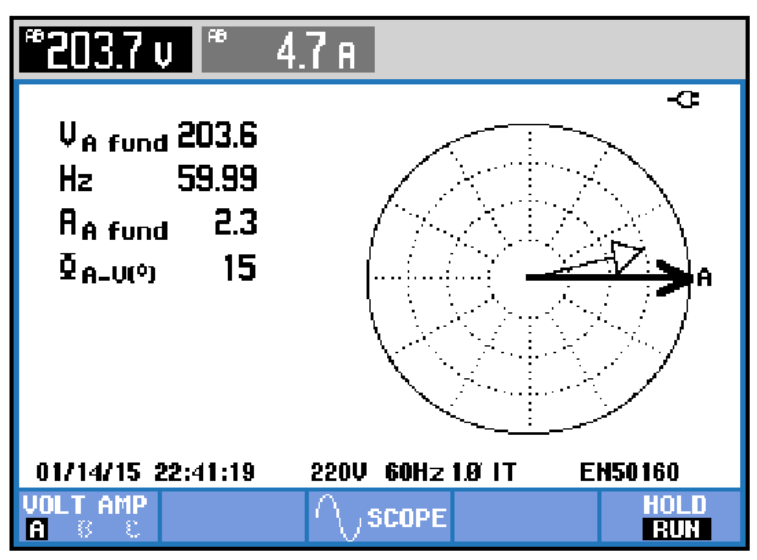

Fig. 9. Vector diagram of voltage and current.

Analyzing Fig. 10, it is observed that the active and reactive power flow on the bus that powers the inverter air conditioning features a $460 \mathrm{~W}$ absorption of active power and a 760VAr injection of capacitive reactive power in the power grid of the utility. Fig. 10 also illustrates the difference between the offset factor that represents the cosine of the angle of current and voltage at $60 \mathrm{~Hz}$ (DPF), whose value is 0.99 , and the power factor $(\mathrm{PF})$ that takes into account all frequencies present in the form of the current waveform, which is a much smaller value and equal to 0.52 . All five meters presented previously made the same power factor and reactive power readings, however we chose to present in Fig. 10 only the measurement recorded by the Fluke 434 .

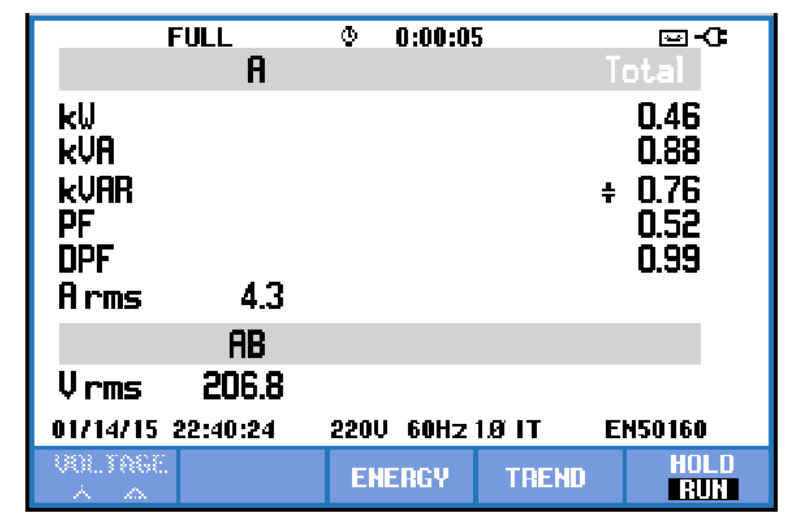

Fig. 10. Screenshot of power quality analyzer Fluke, indicating the capacitive reactive power characteristic injected to the system by inverter split-type air conditioning.

Fig.11 illustrates the absorbed active power and injected reactive power in the bus by the inverter air conditioning, according meters. This chart demonstrates which absorbed active power is well below the injected reactive power.

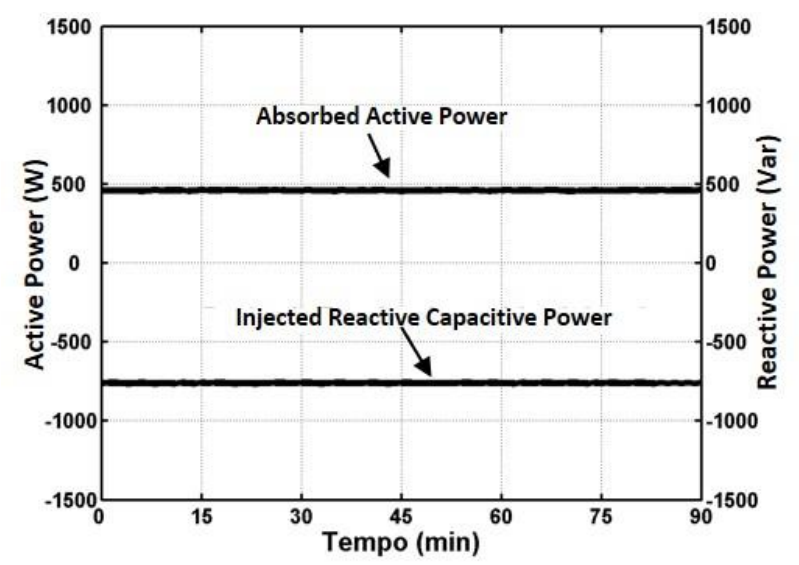

Fig. 11. Absorbed active power and injected capacitive reactive power by inverter split-type air conditioner in the power bus system.

\section{Analysis of measurements}

Analyzing the results obtained in relation to power quality, as showed on table III, it was observed through the energy meters that the Inverter split-type has an active power consumption much lower than conventional split-type, however when the reactive power is analyzed there has been a big difference between which one. While the conventional device had a small absorption of inductive reactive power, the inverter device has a large injection of reactive capacitive power.

The capacitive reactive power injection in bus, registered in the measurement equipment, through split inverter air conditioners can improve the power factor in eighteen hours of inductive time, which requires that the power factor is above 092 inductive, providing a decrease in the reactive power surplus of charged Consumer Units Group A at this time. However, the six additional hours, which requires that the power factor is above 0.92 capacitive, the capacitive feature of these electronic loads injecting reactive on the bus, can increase billed reactive energy surplus of Consumer Units.

Table III. - Experimental Results

\begin{tabular}{|c|c|c|c|c|c|}
\hline Equipment & $\begin{array}{c}\text { Active } \\
\text { Power }\end{array}$ & $\begin{array}{c}\text { Reactive } \\
\text { Power }\end{array}$ & PF & DPF & DTI \\
\hline Conventional & $700 \mathrm{~W}$ & $+200 \mathrm{Var}$ & 0.96 & 0.97 & $12.6 \%$ \\
\hline Inverter & $460 \mathrm{~W}$ & $-760 \mathrm{Var}$ & 0.52 & 0.99 & $153.4 \%$ \\
\hline
\end{tabular}

About the distortion, the Inverter split-type air conditioning presented a total harmonic current distortion around $153.4 \%$, much higher than the distortion presented by conventional split-type air conditioning that was $12.6 \%$. This can lead to a significant increase in RMS current value, due to the strong presence of harmonic positive, negative and zero sequence in the inverter air conditioning. Also a significant increase in zero sequence harmonics can cause an increment in neutral current of systems where these devices are connected. The presence of a current that does not contribute to generation work is highly undesirable in an electric system because it requires a copper conductor cable section greater than that needed for transmission 
from the net power. Furthermore, the presence of this current leads to increased demands in the specifications of power equipment such as transformers, leading to an increase in cost of distribution of electric energy.

\section{Conclusion}

In this paper we analyzed the influence of modern air conditioning equipment in the quality of energy and charging systems when connected on the buses of consumer units in groups A and B. In the measurements, split air conditioners were used, conventional and Inverter, with cooling capacity 9000 BTU / hr. The air inverter showed a strong non-linear feature, due to the frequency inverter used to drive the three-phase of the compressor motor. Its non-linearity provided a high current distortion, with the significant presence of harmonic sequences of positive, negative and zero, which can raise the effective value of the current phases of the bus and the neutral conductor through the circulation of the zero sequence harmonics. Therefore, the bus of the electrical systems Consumer Units of groups A and B, which present a large number of electronic loads must be constantly monitored to verify the heating conditions of the phase conductors and the neutral due to the presence of multiple frequency currents.

Through the data recorded in the power quality analyzers and Energy meters for billing purposes, it was also possible to observe the inverter split-type air conditioner, a capacitive reactive flow to the power bus of the concessionaire. Injection capacitive reactive power at the bus by electronic loads can contribute to changing the power factor of consumer units and consequently influence the reactive power surplus calculation, both inductive time, as the capacitive time. Please note that this equipment has been recommended to group consumers $\mathrm{A}$ and $\mathrm{B}$, to replace the old air conditioners, in order to contribute to greater electrical efficiency, regarding the active power consumption.

Finally, there is the need for further investigation into the methods used by electricity meters in the calculations of the power factor and reactive power, and consequently the impact of injection of this reactive, observed by these meters in the measurement of electronic loads in consumer units of group A and B and their influence on energy charging system. In addition, studies should also include analysis of the interference of the multiple frequencies of the currents injected by non-linear electronic loads in Consumer Units, the buses of the distribution concessionaire of energy and revenue meters.

\section{REFERENCES}

[1] REZENDE, P. H. O., TAVARES, C. E., OLIVEIRA, J. C., ALEGRIAS, J. G. P. A Comparative Analysis of Air Conditioners in the context of Quality and Rationalisation of Energy. X Brazilian Conference on Power Quality, Araxá-MG, 2013.

[2] SUHETT, M. RTechnical Analysis of Reactive Power Measurement in Electronics Meters. Federal University of Rio de Janeiro, 2008
[3] ANEEL. Normative Resolution no 414. September 9th,2010

[4] ANEEL. Electricity Distribution procedures in the National Electric System (Prodist), module 8.

[5] ANEEL. Normative Resolution no 641 January 1th, 2015 